\title{
The Interactive Study Between Facial Expression and Verbal Language of the Discourse Marker So
}

\author{
Qikun Zheng ${ }^{1, a}$ \\ ${ }^{1}$ Foreign Language Department, Tianjin University of Science \& Technology, Tianjin 300222, China \\ ahaunna_zh@163.com
}

Key words: Discourse Markers; Facial expressions; Emotions; Social elements

\begin{abstract}
This study used a subtitle corpus of American TV drama House of Cards SeasonI, Season II and Season III to investigate the utilization of discourse marker so and explore the characteristics of facial expressions' changes and the effects of social elements and personal emotions for text cohesion of the discourse marker so. The results reveal that emotionality facial expression of so is employed most frequently by speakers of this TV drama, and that the facilitating role of facial expression is confirmed where discourse marker so performs its connective functions in discourse coherence.
\end{abstract}

\section{Introduction}

With the development of multimodal discourse analysis, the researchers both abroad and at home have studied not only theoretical but also practical researches on it. One of the initial scholars in this field of multimodal discourse analysis is R. Barthes who has discussed about the interaction of image between expression and language in Image-Music-Text (1977) [1]. Kress \& van Leeuwen (1996, 2001, 2003)[2] study the relationship between modal and the media, especially explore the expression of the significance of multimodal rules, including the role of syntax, color, visual image and the layout of newspaper and different media. However, most studies focus on static discourse, such as the film poster, newspaper and websites, etc, few researchers extend the studies to the dynamic discourses. Li Zhanzi (2003) [3] is the first scholar who introduces the Kress and van Leeuwen's work about visual image to the research of multimodal discourse analysis in China. In order to enrich the former studies, the latter researches need to analyze the synergy for much more semiotic resources, such as sounds, images, facial expressions, and gestures, etc. under a comprehensive analytic framework. According to the background, this thesis chooses the videos of American television series as the research objects. Since television series are typical dynamic multimodal discourse in which multiple modes, such as auditory mode, the verbal mode and the visual mode, they interact with each other to complete the multimodal discourse.

\section{The identification of facial expressions of discourse marker so in House of Cards}

In television series discourse, facial expressions as a on-verbal language can help the characters to express their feelings and attitudes completely which interact with verbal language. According to the Visual Grammar of Kress and van Leeuwen [4], they classified interactive meaning into three aspects, that is, contact, social distance and attitude. In process of interactive communication, facial expressions of participants will be influenced by the three aspects. As what has mentioned above, this thesis divided the facial expressions into three types: 1 ) communicability, the facial expressions of this type often appears in the private time or informal situations; 2) sociability, the facial expressions belong to this type usually shows in some formal places, participants may have a management of facial expressions because of the different places from informal situations; 3) emotionality, when participants' emotion fluctuate strongly or attempt to express their own attitude urgently in conversation, their facial expressions may influenced by these elements and have its characteristics in this process. In order to make the interactive study more vivid and convincing, the thesis made screen shots from the videos to collect relevant images corresponding with the facial 
expression types. Since language will interact with other modes to express meanings, the criterion for capturing screen shots is that: the facial expressions which being analyzed will be reflected when the speakers in television series express sentences containing the corresponding language mode, ie. so. And the distribution of facial expression of discourse marker so as follows in Figure 1.

\section{The interactive analysis of facial expression of discourse marker so.}

The analysis lay in the usage of facial expressions in terms of the communicability, sociability, emotionality and no image. Communication is an activity of transmitting information and we communicate with other people by employing varied of communicative tools. Except language, many other tools such as gestures, facial expressions, sounds are often used to be communicative tools. In order to integrate modalities in our communication, the tight link between language and facial expressions is unnecessary. Further explanation for this link will be illustrated in the following part.

\section{Communicability.}

Communicability can also be called communicative facial expression, it refers to that when people communicating with other people in a private occasion or informal situation, the usage of facial expression may natural and casual, people lie their emphasis on language itself and should not to care other elements too much. An example is presented and the facial expression is illustrated in Figure 2.

(1) Cathy: What do you think of him?

Claire: Petrov? I don't know.

Cathy: You were the one who talked to him all night.

Claire: Well, I didn't have much of a choice.

Cathy: So, not a fan?

Claire: I think he's very intelligent. And he has a charm.

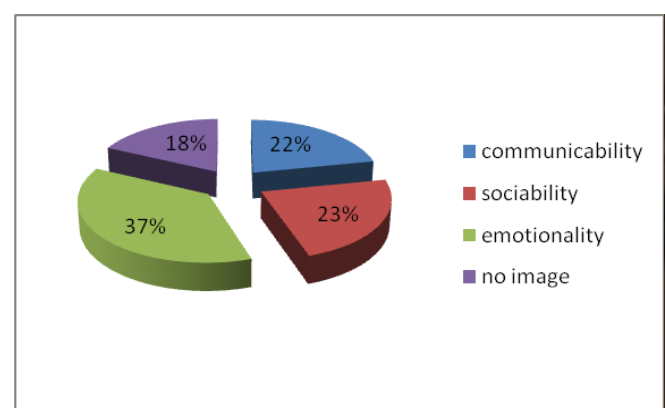

Figure 1

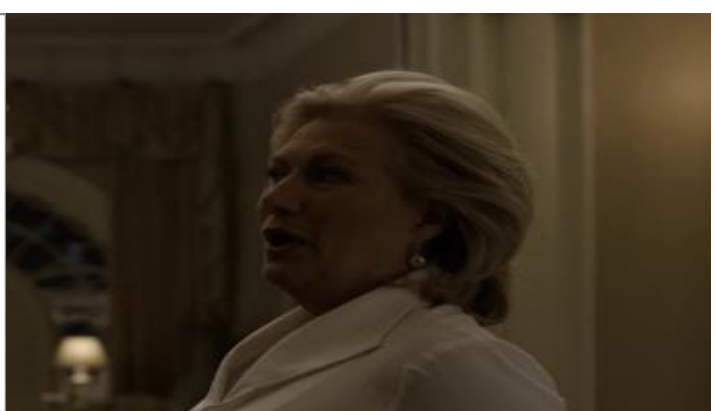

Figure 2

The conversation happens in a private occasion after a party and between two friends, they are talking about something happened in party before. Because the conversation happens in a private occasion and the two people's relationship is close, thus their facial expressions look more informal. As what has mentioned above in Visual Grammar (Kress and van Leeuwen 1996, 2006), the act in Figure belongs to offer act. The woman who speaking is a represented participant and another woman is a viewer, the offer act is formed through two people's utterances and facial expression. Cathy would likes to know whether Claire interested in Petrov, she uses discourse marker so to sound Claire out. There is a direct contact between the two people, it indicates that they feel relax and peace in this occasion, thus their facial expressions are less intense and tend to be peaceful.

\section{Sociability.}

The next facial expression to be discussed is the facial expression which are influenced by social relation and conversation occasion. The speakers' facial expression when using discourse marker so often influenced by people's social status and the communication occasion. For example, people's 
facial expression may looks relax when they are in a general or informal occasion which described in preceding part. Another situation is that when speakers communicating with some who have a higher social status such as leaders or superiors, the speakers' facial expression may becomes more gentle and polite. Examples are presented as follows.

(2) Frank: So, I've spoken to Patricia Whittaker. She's on board. You'll be getting four million in start-up funding from the DNC. I'll pick the team. You announce in August. But the campaign starts today. Are you ready?

Peter: I've already put together a platform.

In this example, two people are talking about the future work plan in Peter's office (in Figure 3). Because the conversation happens in a formal place and the conversation contents are serious, two people treat the conversation seriously. Frank has a higher status than another person involved, thus when he using discourse marker so, his facial expression is gentle and more relax at the same time. He nods his head and smile to his subordinate, it indicates that he is so confidence to the conversation and have the absolute initiative in this relation between himself and the subordinate. On the other hand, his utterance contents show that he is interested in the subordinate and would likes to know the detailed plan of Peter. Frank's facial expression of discourse marker so is not only conform to the conversation occasion and their social distance, but also helps him to express latent meaning of his utterances. It indicates that facial expression can help speaker to express the meaning which he or she has not express through their utterances directly.

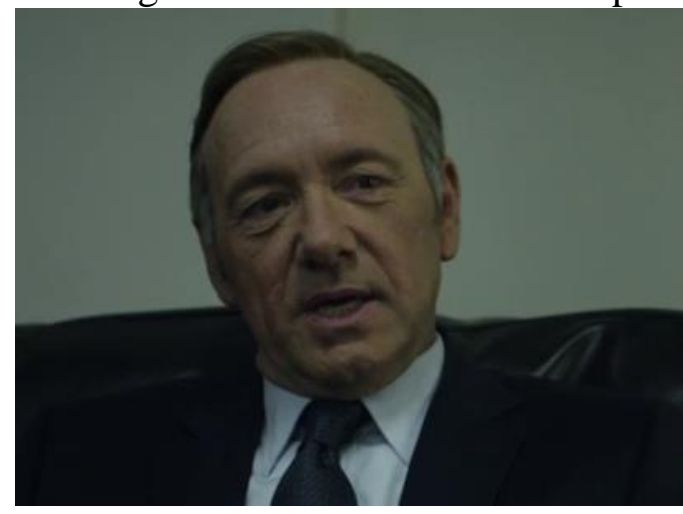

Figure 3.

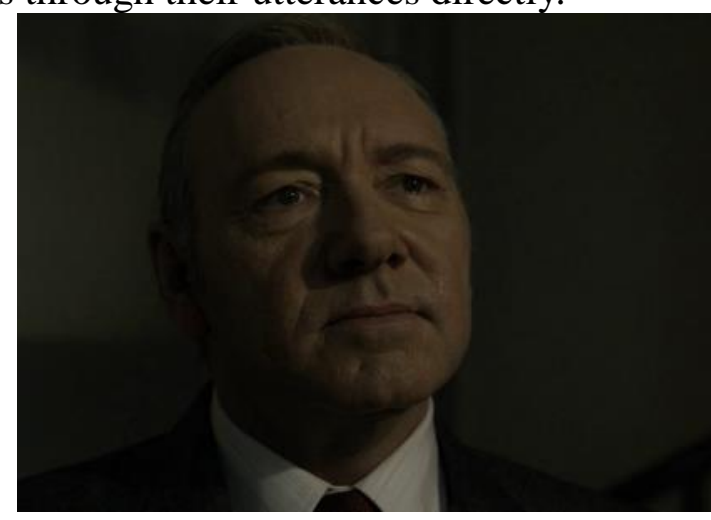

Figure 4.

\section{Emotionality.}

Emotionality refers to the facial expressions that when people communicating with each other, speakers' facial expression has influenced by their emotion in that time, as is known to all, people's facial expression has changed influenced by people's emotion to some extent. Speakers' emotion can expresses through their facial expressions directly in this dynamic discourse, and the emotionality facial expression has the highest frequency among three types of facial expression. It shows that when speakers using discourse marker so to construct the discourse coherence, people's facial expression is most easily affected by emotion. Two examples are illustrated as follows.

(3) Heather: The one you asked Doug to destroy. I wouldn't be so certain that he did it.

Frank: So...you're finally one of us.

In this example of Figure 4, Heather has proposed some requirements to Frank and Frank is hesitates whether he should allow her. Because their have different standpoints about the topic which they are talking about, Frank dissatisfied with Heather's requirements and indicates that he is not to be budged on the issue. As Frank says the discourse marker so, he speaks slowly and stared at Heather seriously, his strong emotion expresses through his facial expression to Heather, and his facial expression has influenced a lot by his emotion. Frank indicates his meaning through his utterances and adds facial expression to help him to express his emotion. Facial expression has the most frequent interaction with speakers' emotion, the interaction between facial expression and utterances contributes to the whole discourse coherence. 


\section{No image.}

Because of the particularity of television series, there are exist the situation that the speaker is not presented in frame when he or she is speaking. The data of no image is also an unnecessary part of the whole corpus, it lets the analysis become more objective and authentic.

\section{Conclusion}

It is widely acknowledged that facial expression is an integral part in the delivery of conversation. The results on drama-facial expression indicates that various facial expressions have multi-dimensional functions. The interaction of facial expressions and utterances could help speakers' expression resources, facilitates hearers' comprehension of meaning delivery and enhance the communicative effect of television series discourse. The facial expression have influenced by the social status and social occasions. Speakers may choose different facial expression according to the conversation occasion or the hearers' social status to some extent. Facial expressions in emotionality are most plentiful and variable, emotion's expression have a intuitional reflection through facial expressions, and emotionality facial expressions of discourse markers so could help speakers express their utterances meaning more completely and vividly. Emotionality facial expression has a high frequency among all types of facial expression in this thesis, it indicates that speakers' facial expressions have influenced by their emotion easily, and the facial expressions assist speakers to express the latent meaning of their utterances.

\section{Acknowledgements}

This work was financially supported by the Shanghai Natural Science Foundation (0666666), Innovation Program of Shanghai Municipal Education Commission (060000) and Shanghai Leading Academic Discipline Project of Shanghai Municipal Education Commission (0555555).

\section{Reference}

[1] Barthes, R. Image-Music-Text[M]. London: Fontana, 1977.

[2] Kress, G and van Leeuwen, T. Reading Image: The Grammar of Visual Design[M]. London: Routledge, 1996/2006.

[3] Li Zhanzi. Social Semiotic Approach to Multimodal Discourse[J]. Foreign Language Research, 2003(5), p, 1-8.

[4] Kress, G and van Leeuwen, T. Multimodal Discourse: The Modes and Media of Contemporary Communication[M]. London: Arnold, 2001. 